\title{
Genetic polymorphism of glutathione S-transferases (GSTM1, GSTT1, and GSTP1) in patients with bullous pemphigoid in a Polish population
}

Mariola Rychlik-Sych¹, Małgorzata Barańska1', Michał Dudarewicz', Jadwiga Skrętkowicz¹, Agnieszka Żebrowska², Jacek Owczarek ${ }^{1}$, Anna Wiktorowska-Owczarek ${ }^{4}$, Daria Orszulak-Michalak ${ }^{3}$, Elżbieta Waszczykowska ${ }^{2}$

${ }^{1}$ Department of Hospital Pharmacy, Laboratory of Pharmacogenetics, Chair of Biopharmacy, Medical University of Lodz, Łódź, Poland

${ }^{2}$ Department of Dermatology and Venereology, Chair of Dermatology and Venereology, Medical University of Lodz, Łódź, Poland

${ }^{3}$ Department of Biopharmacy, Chair of Biopharmacy, Medical University of Lodz, Łódź, Poland

${ }^{4}$ Department of Pharmacology and Toxicology, Medical University of Lodz, Łódź, Poland

Abstract

Introduction. Bullous pemphigoid (BP) is one of the most common bullous diseases with an autoimmune background. The etiology and pathogenesis of BP are believed to be influenced not only by environmental, genetic, and immunological factors as well as by oxidative stress. BP is observed more frequently in elderly patients. Additionally, more potent oxidative stress is observed just in old age. Glutathione S-transferases (GSTs) play key roles in the detoxification of xenobiotics, metabolism of endogenous substrates, and the defense against oxidative stress. The present study examines whether polymorphism of genes encoding three selected GSTs (GSTM1, GSTT1, and GSTP1) might be associated with a higher risk for BP.

Materials and methods. The study involved 71 patients with BP and 100 healthy volunteers from a Polish population. The presence of the deletion type polymorphism for GSTM1 and GSTT1 was confirmed by multiplex PCR. The Ile105Val GSTP1 polymorphism was analyzed by PCR-RFLP.

Results. It was observed that the combination of GSTM1 null/GSTT1 null/GSTP1 Ile/Val, Val/Val genotypes occurred more frequently in patients with BP $(8.5 \%)$ than in controls $(4.0 \%)$. The odds ratio for carriers of GSTM1 null/GSTT1 null/ GSTP1 lle/Val, Val/Val genotypes was $2.22(95 \% \mathrm{Cl} 0.60-8.16 ; p=0.3727)$, but was not statistically significant.

Conclusions. The combination of GSTM1 null, GSTT1 null, GSTP1 lle/Val, Val/Val genotypes might be related to a greater risk of BP in a Polish population. However, future studies including more individuals are required to confirm this.

Keywords

bullous pemphigoid $・$ genetic polymorphism • glutathione S-transferase $・$ oxidative stress

Received: 02.09.2020, Accepted: 25.05.2021

\section{Introduction}

In the etiology and pathogenesis of autoimmune diseases, environmental factors play a significant role, but there has been relatively little examination of the influence of xenobiotics on autoimmune processes or of their development. Upon entering the body, xenobiotics may undergo biotransformation reactions transforming them into active or inactive metabolites or possibly into harmful compounds acting as potential pathogenetic factors. For such diseases, with chemicals and pollutants as relevant etiologic factors, the genetically determined polymorphism of biotransformation seems to have a key role.

The transformation of xenobiotics is commonly divided into phase I (oxidation, reduction, and hydrolysis) and phase II (conjugation) reactions [1, 2].
Glutathione S-transferase (GST), with its various isoforms, belongs to the enzymes that catalyze the phase II processes. GSTs generally act as detoxifiers, catalyzing the conjugation of endogenous glutathione (GSH) with electrophilic metabolites emerging from phase I, as well as removing the reactive metabolites produced during oxidative stress, such as alphaand beta-unsaturated ketones, quinones, and hydroperoxides [3]. These transferases also protect against the action of reactive oxygen species (ROS), which cause damage to nucleic acids, proteins, or lipids and are involved in the pathogenesis of many diseases $[4,5]$.

Most GSTs are polymorphic, and each polymorphism may potentially affect the body's susceptibility to the action of xenobiotics, including air pollutants, carcinogens, pesticides, insecticides, and many medicines. In addition, as these enzymes enable to the metabolism of different kinds xenobiotics and 
endogenous substrates, any factor that alters their expression in certain tissues may be an important diagnostic indicator [6, 7]. Polymorphisms have been identified in GSTM1, GSTT1, and GSTP1, which encode the respective isozymes GSTM1, GSTT1, and GSTP1. Genetic polymorphisms that affect the activity of GSTs are typically single nucleotide polymorphisms (SNPs), known to be present in the coding and noncoding regions, as well as deletions or duplications within a given gene [8].

The GSTM1 gene is found on chromosome 1 (region 1p13.3). A homozygous deletion of this gene (GSTM1 null), which occurs with the frequency of nearly $50 \%$ in the Caucasian population, results in shutting off enzymatic activity and hence xenobiotic biotransformation. It has been shown that, following occupational exposure to halogen hydrocarbons, individuals with the GSTM1 null genotype had more than a six-fold greater risk of bladder cancer compared with those with the wild-type genotype [9].

The GSTT1 gene lies on chromosome 22q11.23, and a GSTT1 deletion has also been described. A lack of GSTT1 activity may affect the toxicity of antineoplastic drugs and the effectiveness of chemotherapy and could be responsible for a greater intensity of adverse drug reactions [10].

The GSTP1 gene, in turn, is placed on chromosome 11q13. One of its better known alterations is the presence of an SNP in exon $5(A \rightarrow G$ substitution at nucleotide 313$)$, which results in the formation of a non-synonymous amino acid substitution at position 105 (lle $\rightarrow$ Val). The A313G polymorphism has been associated with either an increase or a decrease in GSTP1 catalytic activity [11]. It has been suggested that this polymorphism might influence the affinity of the enzyme to substrates such as ROS [12]. The A313G substitution might also be linked to an elevated risk of breast cancer [13, 14], lung cancer [15], and bladder cancer in smokers $[16,17]$.

Bullous pemphigoid (BP) is one of the most common bullous diseases with an autoimmune background. It is usually diagnosed among individuals at the age of 65 years and over, with those aged over 80 years being the most numerous group. The entity is thought to develop as a result of dysfunctional response to certain autoantigens: the elements of hemidesmosomes and the basement membrane of the epidermis. The main ones are the hemidesmosomal proteins BP180 and BP230 [18, 19, 20].

The etiology and pathogenesis of BP remain unclear. There is some evidence that besides immunological and genetic factors, environmental factors also play an important role in the pathomechanism of $\mathrm{BP}[18,21]$.

One such factor is oxidative stress [22]. Skin is constantly exposed to chemical and physical factors, such as pollutants and UV light; exposure is believed to lead to increased ROS production, as well as increased enzymes and immune system activity, thus contributing to elevated oxidative stress and depletion of resources intended for endogenous antioxidants [23].

Glutathione S-transferases are involved in the detoxification of many xenobiotics, the metabolism of endogenous substrates, and the defense against oxidative stress. Hence, the presence of genetic polymorphisms that affect the activity of particular enzymes may be significant determinants of individual risk for several diseases, especially when their etiology is related to exposure to environmental factors. Therefore, the present study examines whether the presence of polymorphisms of genes encoding three selected GSTs (GSTM1, GSTT1, and GSTP1) might be associated with a higher risk of BP.

\section{Materials and Methods}

The study involved a total of 171 individuals: 71 patients with BP (the study group) and 100 healthy volunteers (the control group). The patients were treated in the Department of Dermatology and Venereology, Medical University of Lodz, Poland. The age of the BP group ranged from 29 to 92 years (mean $\pm S D, 66.3 \pm 15.0$ ), and the control group from 19 to 75 years (mean $\pm S D, 36.9 \pm 12.5$ ). All patients were at the active stage of the disease, before administration of any (systemic or topical) treatment, with a mean BPDAl (Bullous Pemphigoid Disease Activity Index) of $39 \pm 16$ (Table 1).

In all cases, the histopathologic findings, according to Ackerman, were fully developed. The specimens showed neutrophilic, eosinophilic, and lymphocytic infiltrates in the dermis of all patients, which in most cases were accompanied by subepidermal blisters. The direct immune fluorescence (IF) test revealed the presence of $\lg G$ and/or C3 linear deposits along the basement membrane zone (BMZ) in all cases. The $1 \mathrm{M} \mathrm{NaCl}$ split test identified deposits in the epidermal side of the blister or in the epidermal and dermal side of the split. Indirect IF microscopy revealed the presence of circulating IgG antibodies in patient sera during incubation with monkeys' esophagi [24]. Antibodies were found in $70 \%$ of all patients, in titers ranging from 1:80 to 320 (median: 1:160).

The protocol of this study was approved by the Bioethics Committee on Research in Humans at Medical University of Lodz, Poland.

Genomic DNA was extracted from peripheral blood leukocytes using the Gene MATRIX Quick Blood DNA Purification Kit (EURx Ltd., https://eurx.com.pl/main/), following the protocol from the manufacturer. The GSTM1 and GSTT1 polymorphisms were identified by multiplex PCR according to Gorukmez et al. [25]. Briefly, three pairs of primers were added to the master mix: the first for GSTM1, the second for GSTT1, and the third one for the 
Table 1. Demographic and clinical characteristics of study participants

\begin{tabular}{|c|c|c|c|c|c|}
\hline & $\begin{array}{l}\text { Sex } \\
\mathrm{n}(\%)\end{array}$ & $\begin{array}{c}\text { Age } \\
(\text { mean } \pm S D)\end{array}$ & $\begin{array}{c}\text { BDAl } \\
\text { (mean } \pm \text { SD) }\end{array}$ & VAS (itching) & Anti-BMZ antibodies \\
\hline \multirow{2}{*}{$\begin{array}{l}\text { Patients with BP } \\
\quad n=71\end{array}$} & F: 47 (66.2) & & & & \\
\hline & & $66.3 \pm 15.0$ & $39 \pm 16$ & $\begin{array}{c}4-10 \\
\text { (median 8) }\end{array}$ & $1: 80$ to $1: 320$ (median $1: 160$ ) \\
\hline \multirow{2}{*}{$\begin{array}{c}\text { Controls } \\
n=100\end{array}$} & $F: 45(45)$ & & & & \\
\hline & M: 55 (55) & $36.9 \pm 12.5$ & - & - & - \\
\hline
\end{tabular}

BDAI - Bullous Pemphigoid Disease Activity Index, VAS - Visual Analogue Scale, BMZ - Basement Membrane Zone, SD - standard deviation

gene encoding albumin (a positive control). The products of the multiplex PCR were analyzed electrophoretically in a $2 \%$ agarose gel, dyed with ethidium bromide and visualized under ultraviolet light. The following bands were identified: 459 bp (GSTT1), 350 bp (albumin), and 219 bp (GSTM1). This method indicated the presence or deletion of GSTM1 and GSTT1.

The lle105Val (A313G) GSTP1 polymorphism was determined by PCR-RFLP (restriction fragment length polymorphism) according to Abbas et al. [26]. Briefly, amplification products were digested with the BsmAl restriction enzyme (New England BioLabs, Inc.) and analyzed electrophoretically in a $4 \%$ agarose gel. If a product of $176 \mathrm{bp}$ was formed, the sample was defined as having the Val/Val (313GG) genotype. If three bands of $176 \mathrm{bp}, 91 \mathrm{bp}$, and 85 bp were present, the sample was defined as having the Ile/ Val (313AG) genotype. Products of $85 \mathrm{bp}$ and $91 \mathrm{bp}$ indicated the presence of the lle/lle (313AA) genotype [26].

The frequency of particular alleles and genotypes in patients with BP was compared with those in the control group of healthy volunteers using the chi-square test. In addition, the genotypes were tested for accordance with the HardyWeinberg equilibrium. Our results are based on the odds ratio (OR) with a 95\% confidence interval (Cl). For all statistical analyses, the level of significance was set at $5 \%(p<0.05)$. The calculations were performed with the STATISTICA 13.3 data analysis software system (StatSoft, Inc., Poland).
The frequency of genotypes and alleles for the lle105Val GSTP1 polymorphism is shown in Table 3. No significant differences in the frequencies of particular genotypes for the GSTP1 polymorphism were observed between the two groups. The Val/Val (313GG) GSTP1 genotype was found to be more widespread among the BP patients than controls ( $7 \%$ vs. $4 \%, p=0.5958$ ); however, the difference was not statistically relevant. Carriers of the Val/Val genotype were shown to have an increased risk of $\mathrm{BP}(\mathrm{OR}=1.82,95 \% \mathrm{Cl}$ 0.47-7.03; $p=0.5958$ ).

No significant differences were found between the groups regarding the frequency of alleles for the lle105Val polymorphism ( $p=0.7118)$.

The combinations of GSTM1, GSTT1, and GSTP1 polymorphisms observed in the two groups are depicted in Table 4. It is noteworthy that a combination of GSTM1 null/ GSTT1 null/GSTP1 Ile/Val, Val/Val occurred more frequently in patients with BP $(8.5 \%)$ than in controls $(4.0 \%)$. The OR for carriers of GSTM1 null/GSTT1 null/GSTP1 lle/Val, and $\mathrm{Val} / \mathrm{Val}$ genotypes was 2.22 (95\% Cl 0.60-8.16; $p=0.3727$ ); however, this value was not statistically significant. In addition, the combination of GSTM1 non-null/GSTT1 null/GSTP1 lle/ Val, Val/Val increased this risk by more than fourfold (OR = 4.37) and was more often present in the BP group than in controls $(4.2 \%$ vs. $1.0 \%)$. Likewise, the relationship was not statistically significant (0.3889), and the $95 \%$ confidence interval for OR ranged from 0.44 to even 42.88 .

\section{Results}

The frequency of GSTM1 and GSTT1 polymorphisms in the BP patient group and the control group is depicted in Table 2. No statistically significant differences were observed between BP patients and healthy volunteers with respect to the frequency of individual and double GSTM1 and GSTT1 genotypes $(p>0.05)$.

\section{Discussion}

The etiology and pathogenesis of autoimmune diseases are multifactorial, requiring both genetic and environmental factors to be present. Within the group of bullous diseases with an autoimmune background, bullous pemphigoid (BP) is the most common entity, especially among the elderly. The condition is manifested as the formation of subepidermal blisters, a process that is contingent on the presence of 
Table 2. Association of GSTM1 and GSTT1 polymorphisms with the risk of BP

\begin{tabular}{|c|c|c|c|c|}
\hline Polymorphism & $\begin{array}{c}\text { BP } n=71 \\
n(\%)\end{array}$ & $\begin{array}{c}\text { Controls } n=100 \\
n(\%)\end{array}$ & $p$-value & OR $(95 \% \mathrm{Cl})$ \\
\hline GSTM1 non-null & $29(40.8)$ & $48(48)$ & 0.3541 & $0.75(0.40-1.38)$ \\
\hline GSTM1 null & $42(59.2)$ & $52(52)$ & 0.3541 & $1.34(0.72-2.47)$ \\
\hline GSTT1 non-null & $51(71.8)$ & $76(76)$ & 0.5389 & $0.81(0.40-1.61)$ \\
\hline GSTT1 null & $20(28.2)$ & $24(24)$ & 0.5389 & $1.24(0.62-2.48)$ \\
\hline \multicolumn{5}{|c|}{ Double polymorphisms } \\
\hline $\begin{array}{c}\text { GSTM1/GSTT1 } \\
\text { non-null/non-null }\end{array}$ & $20(28.2)$ & $37(37)$ & 0.2274 & $0.67(0.35-1.29)$ \\
\hline $\begin{array}{l}\text { GSTM1/GSTT1 } \\
\text { null/non-null }\end{array}$ & $31(43.6)$ & $39(39)$ & 0.5412 & $1.21(0.65-2.25)$ \\
\hline $\begin{array}{c}\text { GSTM1/GSTT1 } \\
\text { non-null/null }\end{array}$ & $9(12.7)$ & $11(11)$ & 0.7368 & $1.17(0.46-3.00)$ \\
\hline $\begin{array}{c}\text { GSTM1/GSTT1 } \\
\text { null/null }\end{array}$ & $11(15.5)$ & $13(13)$ & 0.6437 & $1.23(0.52-2.92)$ \\
\hline
\end{tabular}

$\mathrm{BP}$ - bullous pemphigoid, $\mathrm{p}$ - significance level (significant differences at $\mathrm{p}<.05$ ), OR - odds ratio, $95 \% \mathrm{Cl}$ - $95 \%$ confidence interval

Table 3. The distribution of particular genotypes and alleles for the lle105Val GSTP1 polymorphism in the group of BP patients and in the control group

\begin{tabular}{|c|c|c|c|c|}
\hline Ile105Val GSTP1 polymorphism & $\begin{array}{c}\text { BP } \\
\mathrm{n}=71 \\
\mathrm{n}(\%)\end{array}$ & $\begin{array}{c}\text { Controls } n=100 \\
n(\%)\end{array}$ & p-value & OR $(95 \% \mathrm{Cl})$ \\
\hline \multicolumn{5}{|l|}{ Genotype } \\
\hline Ile/lle (wild type) & $46(64.8)$ & $65(65)$ & 0.9772 & $0.99(0.52-1.87)$ \\
\hline Ile/Val & $20(28.2)$ & $31(31)$ & 0.6901 & $0.87(0.45-1.70)$ \\
\hline Val/Val & $5(7.0)$ & $4(4)$ & 0.5958 & $1.82(0.47-7.03)$ \\
\hline \multicolumn{5}{|l|}{ GSTP1 } \\
\hline Ile/lle (wild type) & $46(64.8)$ & $65(65)$ & 0.9772 & $0.99(0.52-1.87)$ \\
\hline Ile/Val and $\mathrm{Val} / \mathrm{Val}$ & $25(35.2)$ & $35(35)$ & 0.9772 & $1.01(0.53-1.91)$ \\
\hline \multicolumn{5}{|l|}{ Allele } \\
\hline lle & $112(78.9)$ & $161(80.5)$ & 0.7118 & $0.90(0.53-1.54)$ \\
\hline Val & $30(21.1)$ & $39(19.5)$ & 0.7118 & $1.11(0.65-1.89)$ \\
\hline
\end{tabular}

BP - bullous pemphigoid, $\mathrm{p}$ - significance level (significant differences at $\mathrm{p}<.05$ ), OR - odds ratio, $95 \% \mathrm{Cl}$ - $95 \%$ confidence interval

autoantibodies against various antigens of the basement membrane. In addition to idiopathic forms, many cases are known to have been induced by UV radiation, infections, thermal burns, and medicines [18].

Recently, oxidative stress has also been identified as a potential triggering mechanism [22]. The skin, as an organ, is constantly attacked by ROS from endogenous and exogenous sources. ROS are essential in numerous biological reactions; however, generated in excess quantities, they can be noxious. Free radicals damage proteins by aggregation and denaturation; they also influence lipids by peroxidation, modify carbohydrates, and alter nucleotides by inducing mutation [23].

Glutathione S-transferase (GST) plays a crucial role in the reduction and detoxification of $\operatorname{ROS}[27,28]$. Recent evidence indicates that immunoglobulins associated with BP ( $\operatorname{lgG}$ ) induce the production of ROS, thus significantly reducing the stability of the cell membrane [29].

Under physiological conditions, ROS arise as intermediates of metabolism in the mitochondria, where 
Table 4. The combined effect of GST polymorphisms on the risk of BP

\begin{tabular}{|c|c|c|c|c|c|c|}
\hline \multicolumn{3}{|c|}{ GSTs polymorphisms } & \multirow{2}{*}{$\begin{array}{c}\text { BP } \\
\mathrm{n}=71 \\
\mathrm{n}(\%)\end{array}$} & \multirow{2}{*}{$\begin{array}{c}\text { Control } n=100 \\
n(\%)\end{array}$} & \multirow{2}{*}{$p$-value } & \multirow{2}{*}{$\begin{array}{c}\text { OR } \\
(95 \% \mathrm{Cl})\end{array}$} \\
\hline GSTM1 & GSTT1 & GSTP1 & & & & \\
\hline Non-null & Non-null & Ile/lle & $\begin{array}{c}14 \\
(19.7)\end{array}$ & $\begin{array}{c}23 \\
(23.0)\end{array}$ & 0.6076 & $\begin{array}{c}0.82 \\
(0.39-1.74)\end{array}$ \\
\hline Non-null & Null & Ile/lle & $\begin{array}{c}6 \\
(8.5)\end{array}$ & $\begin{array}{c}10 \\
(10.0)\end{array}$ & 0.7318 & $\begin{array}{c}0.83 \\
(0.29-2.40)\end{array}$ \\
\hline Null & Non-null & Ile/lle & $\begin{array}{c}21 \\
(29.6)\end{array}$ & $\begin{array}{c}23 \\
(23.0)\end{array}$ & 0.3323 & $\begin{array}{c}1.41 \\
(0.70-2.80)\end{array}$ \\
\hline Null & Null & Ile/lle & $\begin{array}{c}5 \\
(7.0)\end{array}$ & $\begin{array}{c}9 \\
(9.0)\end{array}$ & 0.8594 & $\begin{array}{c}0.77 \\
(0.25-2.39)\end{array}$ \\
\hline Non-null & Null & Ile/Val, Val/Val & $\begin{array}{c}3 \\
(4.2)\end{array}$ & $\begin{array}{c}1 \\
(1.0)\end{array}$ & 0.3889 & $\begin{array}{c}4.37 \\
(0.44-42.88)\end{array}$ \\
\hline Null & Non-null & Ile/Val, Val/Val & $\begin{array}{c}11 \\
(15.5)\end{array}$ & $\begin{array}{c}16 \\
(16.0)\end{array}$ & 0.9286 & $\begin{array}{c}0.96 \\
(0.42-2,22)\end{array}$ \\
\hline Null & Null & Ile/Val, Val/Val & $\begin{array}{c}6 \\
(8.5)\end{array}$ & $\begin{array}{c}4 \\
(4.0)\end{array}$ & 0.3727 & $\begin{array}{c}2.22 \\
(0.60-8.16)\end{array}$ \\
\hline Non-null & Non-null & Ile/Val, Val/Val & $\begin{array}{c}5 \\
(7.0)\end{array}$ & $\begin{array}{c}14 \\
(14.0)\end{array}$ & 0.2381 & $\begin{array}{c}0.47 \\
(0.16-1.36)\end{array}$ \\
\hline
\end{tabular}

$\mathrm{BP}$ - bullous pemphigoid, $\mathrm{p}$ - significance level (significant differences at $\mathrm{p}<.05$ ), OR - odds ratio, $95 \% \mathrm{Cl}$ - $95 \%$ confidence interval

phosphorylation and electron transport chain take place, and in phagocytes, which employ NADPH oxidase [30].

$\mathrm{BP}$ is most commonly associated with the elderly, who are more likely to demonstrate dysfunctions in the mitochondria and more potent oxidative stress [31, 32]. Excessive amounts of ROS may contribute to autoimmunization, particularly in the elderly, who tend to display lower antioxidant potential. Studies have examined the influence of oxidative stress and specific variant alleles of genes encoding GSTs on the onset and development of exacerbations of autoimmune diseases [33, 34].

In the late 1990s, it was known that a lack of GSTM1 and GSTT1 activity associated with the presence of null genotypes allows for ROS to accumulate and induce apoptosis in the course of systemic lupus erythematosus (SLE). This apoptosis, in turn, may cause keratinocytes to expose autoantigens, such as the Rho antigen, leading to the generation of autoantibodies associated with the disease [35].

It has also been reported that GSTM1 null, GSTT1 null genotypes, and the Ile GSTP1 variant might be associated with an increase in the risk of SLE, as the GSTT1 null genotype was found to be more common in patients with SLE than in controls, and the combination of GSTM1 null/ GSTT1 null was related to a 2.8-fold higher risk of SLE. In addition, the combination of GSTM1 null/GSTT1 null/GSTP1 Ile/ $\mathrm{Val}$, and $\mathrm{Val} / \mathrm{Val}$ genotypes enhanced this risk eight-fold [36]. However, Glesse et al. suggest that the Ile/Val GSTP1 genotype (heterozygous) protects Europeans against SLE [37].
Fraser et al. report that the GSTM1 genotype might modify the effect of occupational sun exposure on the risk for SLE in Caucasians [38]. In their study, carriers of the GSTM1 null genotype demonstrated a three-fold greater risk (OR = $3.1,95 \% \mathrm{Cl} 0.9-10.8)$ of SLE associated with occupational sun exposure lasting 24 hours per month and above. This risk was not increased in individuals with the GSTM1 nonnull genotype $(\mathrm{OR}=0.6,95 \% \mathrm{Cl} 0.3-1.5)$, and the interaction was statistically relevant $(p=0.028)$.

It has been proposed that the genes controlling the synthesis of GSTs may have an essential role in modulating the predisposition to SLE [39]. Karlson et al. found that the disease occurred at an earlier age in African American women who were GSTM1-deficient, exhibited altered GSTP1 substrate-binding sites, and lived in areas where hazardous waste was stored [39].

Genetic polymorphisms in glutathione transferases may also play a significant role in the course of systemic sclerosis (SSc). Tew et al. report that the frequency of the GSTT1 null genotype was markedly greater among SSc patients with hypertension and structural changes in lungs [40]. In addition, Palmer et al. found the Val allele for the GSTP1 polymorphism to be poorly associated with a predisposition to SSc in Caucasians; however, they noted that individuals with combined GSTM1 null, GSTT1 null, and GSTP1 Val/ Val genotypes were at a higher risk of atherosclerosis in the disease course [41].

Our present findings failed to indicate that the presence of polymorphisms in genes encoding three selected GSTs significantly influences the risk of BP in a Polish population. No relevant differences in the frequency of analyzed GSTM1, 
GSTT1, and GSTP1 polymorphisms were observed between the group of BP patients and the controls. Despite this, the $\mathrm{BP}$ risk was slightly higher in carriers of the Val/Val (variant) GSTP1 genotype ( $\mathrm{OR}=1.82,95 \% \mathrm{Cl} 0.47-7.03 ; p=0.5958)$, and the combination of GSTM1 null, GSTT1 null, GSTP1 lle/ $\mathrm{Val}, \mathrm{Val} / \mathrm{Val}$ increased this risk more than two-fold $(\mathrm{OR}=2.22$, $95 \% \mathrm{Cl} 0.60-8.16 ; p=0.3727$ ). These relationships were not statistically significant (Table 4).

Unfortunately, although the combination of GSTM1 null, GSTT1 null, GSTP1 lle/Val, Val/Val genotypes might be related to an increase in the risk for BP, our findings do not offer an unequivocal answer, and prospective studies including more individuals are required to confirm this association. Previous studies suggest that this combination significantly raised the risk of SLE and affected the course of SSc, thus highlighting the role of the GSTM1, GSTT1, and GSTP1 polymorphisms in autoimmune diseases, of which $\mathrm{BP}$ is one. Here it should be added that there are two main limitations concerning the results of our work. The first is the age difference between both groups, which results from a higher prevalence of BP in the elderly. The second one is that because BP is a rare disease, enrolling a large group of patients takes time.

Assuming that environmental factors play a substantial role in the development of $\mathrm{BP}$, further research on the relevance of polymorphisms in genes that encode GST isoenzymes is certainly justified. BP is most commonly observed among the elderly, who are more subject to oxidative stress. Moreover, ROS not only play an important role in the etiology and pathogenesis of autoimmune diseases but also in their clinical course.

The combination of GSTM1 null, GSTT1 null, GSTP1 lle/ Val, Val/Val genotypes might be related to a greater risk of BP in a Polish population. However, future studies including more individuals are required to confirm this.

\section{Abbreviations}

95\% Cl: 95\% confidence interval; BMZ: basement membrane zone; BP: bullous pemphigoid; BP180 and BP230: hemidesmosomal proteins clinically associated with BP; BPDAl: bullous pemphigoid disease activity index; GSH: the reduced form of glutathione; GST: glutathione S-transferase; GSTM1, GSTT1, and GSTP1: respective isozymes of GST; HLA: human leukocyte antigen; IF: immune fluorescence; Ig: immunoglobulin; IL: interleukin; OR: odds ratio; $\boldsymbol{p}$ : the level of statistical significance; PCR: polymerase chain reaction; PCR-RFLP: polymerase chain reaction restriction fragment length polymorphism; ROS: reactive oxygen species: SD: standard deviation; SLE: systemic lupus erythematosus; SNP: single nucleotide polymorphism; SSc: systemic sclerosis; UV: ultraviolet light; VAS: Visual Analogue Scale.

\section{Authors' Contributions}

M.R.-S.: Carrying out the experiments, analysis, and interpretation of data; writing the manuscript, literature review; M.B.: Carrying out the experiments, analysis and interpretation of data, literature review; M.D.: Analysis and interpretation of data, writing the manuscript; J.S.: Research concept and design, final proofreading, and approval of the version for publication; A.Ż.: Acquisition of data, analysis and interpretation of data; J.O.: Supervising the project, drafting the article or revising it critically for important intellectual content, final proofreading and approval of the version for publication; A.W.-O.: Acquisition of data, analysis and interpretation of data; D.O.-M.: Research concept and design, drafting the article or revising it critically for important intellectual content; E.W.: Research concept and design, drafting the article or revising it critically for important intellectual content, acquisition of data, final proofreading, and approval of the version for publication.

\section{Funding}

This work was supported by grants No. 503/3-011-03/50331-001-19-00 and No. 503/1-152-01/503-11-002 from the Medical University of Lodz, Łódź, Poland.

\section{Conflict of Interest}

The authors have no potential conflicts of interest to declare.

\section{Ethics Approval}

The protocol of this study was approved by the Bioethics Committee on Research in Humans at the Medical University of Lodz, Poland.

\section{References}

[1] Mahid S.S., Colliver D.W., Crawford N.P., Martini B.D., Doll M.A., Hein D.W., Cobbs G.A., Petras R.E., Galandiuk S.: Characterization of $\mathrm{N}$-acetyltransferase 1 and 2 polymorphisms and haplotype analysis for inflammatory bowel disease and sporadic colorectal carcinoma. BMC Med. Genet., 2007; 8: 28

[2] Rychlik-Sych M., Skrętkowicz J.: Metabolizm leków. Farm. Pol., 2008; 64: 51-60 
[3] Sheehan D., Meade G., Foley V.M., Dowd C.A.: Structure, function and evolution of glutatione transferases: Implications for classification of non-mammalian members of an ancient enzyme superfamily. Biochem. J., 2001; 360: 1-16

[4] Gallagher E.P., Gardner J.L., Barber D.S.: Several glutathione Stransferase isozymes that protect against injury are expressed in human liver mitochondria. Biochem. Pharmacol., 2006; 71: 1,6191,628

[5] Marchewka Z., Piwowar A., Ruzik S., Długosz A.: Glutathione Stransferases class $\mathrm{Pi}$ and $\mathrm{Mi}$ and their significance in oncology. Postępy Hig. Med. Dośw., 2017; 71: 541-550

[6] Kerb R., Brockmöller J., Reum T., Roots I.: Deficiency of glutathione S-transferases T1 and M1 as heritable factors of increased cutaneous UV sensitivity. J. Invest. Dermatol., 1997; 108: 229-232

[7] Strange R.C., Spiteri M.A., Ramachandran S., Fryer A.A.: Glutathione-S-transferase family of enzymes. Mutat. Res., 2001; 482: $21-26$

[8] Lo H.W., Ali-Osman F.: Genetic polymorphism and function of glutathione S-transferases in tumor drug resistance. Curr. Opin. Pharmacol., 2007; 7: 367-374

[9] Matic M.G., Coric V.M., Savic-Radojevic A.R., Bulat P.V., PljesaErcegovac M.S., Dragicevic D.P., Djukic T.I., Simic T.P., Pekmezovic T.D.: Does occupational exposure to solvents and pesticides in association with glutathione S-transferase A1, M1, P1, and T1 polymorphisms increase the risk of bladder cancer? The Belgrade Case-Control Study. PLoS One, 2014; 9: e99448

[10] Bolt H.M., Thier R.: Relevance of the deletion polymorphisms of the glutathione S-transferases GSTT1 and GSTM1 in pharmacology and toxicology. Curr. Drug Metab., 2006; 7: 613-628

[11] Board P.G., Menon D.: Glutathione transferases, regulators of cellular metabolism and physiology. Biochim. Biophys. Acta, 2013; 1830: 3,267-3,288

[12] Fryer A.A., Bianco A., Hepple M., Jones P.W., Strange R.C., Spiteri M.A.: Polymorphism at the glutathione S-transferase GSTP1 locus. A new marker for bronchial hyperresponsiveness and asthma. Am. J. Respir. Crit. Care Med., 2000; 161: 1,4371,442

[13] Dumitrescu R.G., Cotarla I.: Understanding breast cancer riskwhere do we stand in 2005? J. Cell. Mol. Med., 2005; 9: 208-221

[14] Jardim B.V., Moschetta M.G., Gelaleti G.B., Leonel C., Regiani V.R., de Santi Neto D., Bordin-Junior N.A., Perea S.A., Zuccari D.A.: Glutathione transferase pi (GSTpi) expression in breast cancer: An immunohistochemical and molecular study. Acta Histochem., 2012; 114: 510-517

[15] Strange R.C., Fryer A.A.: The glutathione S-transferases: Influence of polymorphism on cancer susceptibility. IARC Sci. Publ., 1999; 148: 231-249

[16] Habdous M., Siest G., Herbeth B., Vincent-Viry M., Visvikis S.: Glutathione S-transferases genetic polymorphisms and human diseases: Overview of epidemiological studies. Ann. Biol. Clin., 2004; 62: 15-24
[17] Pljesa-Ercegovac M., Savic-Radojevic A., Dragicevic D., MimicOka J., Matic M., Sasic T., Pekmezovic T., Vuksanovic A., Simic T.: Enhanced GSTP1 expression in transitional cell carcinoma of urinary bladder is associated with altered apoptotic pathways. Urol. Oncol., 2011; 29: 70-77

[18] Lo Schiavo A., Ruocco E., Brancaccio G., Caccavale S., Ruocco V., Wolf R.: Bullous pemphigoid: Etiology, pathogenesis, and inducing factors: Facts and controversies. Clin. Dermatol., 2013; 31: 391-399

[19] Schmidt E., Reimer S., Kruse N., Jainta S., Bröcker E.B., Marinkovich M.P., Giudice G.J., Zillikens D.: Autoantibodies to BP180 associated with bullous pemphigoid release interleukin-6 and interleukin-8 from cultured human keratinocytes. J. Invest. Dermatol., 2000; 115: 842-848

[20] Waszczykowska E., Wysoczańska K., Żebrowska A.: The role of cytokines in the pathogenesis of autoimmune bullous skin disease. Alerg. Astma Immun., 2004; 9: 179-186

[21] Zakka L.R., Reche P., Ahmed A.R.: Role of MHC Class II genes in the pathogenesis of pemphigoid. Autoimmun. Rev., 2011; 11: $40-47$

[22] de Graauw E., Sitaru C., Horn M.P., Borradori L., Yousefi S., Simon D., Simon H.U.: Monocytes enhance neutrophil-induced blister formation in an ex vivo model of bullous pemphigoid. Allergy, 2018; 73: 1,119-1,130

[23] Shah A.A., Sinha A.A.: Oxidative stress and autoimmune skin disease. Eur. J. Dermatol., 2013; 23: 5-13

[24] Otten J.V., Hashimoto T., Hertl M., Payne A.S., Sitaru C.: Molecular diagnosis in autoimmune skin blistering conditions. Curr. Mol. Med., 2014; 14: 69-95

[25] Gorukmez O., Yakut T., Gorukmez O., Sag S.O., Topak A., Sahinturk S., Kanat O.: Glutathione S-transferase T1, M1 and P1 genetic polymorphisms and susceptibility to colorectal cancer in Turkey. Asian Pac. J. Cancer Prev., 2016; 17: 3,855-3,859

[26] Abbas A., Delvinquiere K., Lechevrel M., Lebailly P., Gauduchon P., Launoy G., Sichel F.: GSTM1, GSTT1, GSTP1 and CYP1A1 genetic polymorphisms and susceptibility to esophageal cancer in a French population: Different pattern of squamous cell carcinoma and adenocarcinoma. World J. Gastroenterol., 2004; 10: 3,389-3,393

[27] Kulbacka J., Saczko J., Chwiłkowska A.: Oxidative stress in cells damage processes. Pol. Merk. Lekarski, 2009; 27: 44-47

[28] Sheu S.S., Nauduri D., Anders M.W.: Targeting antioxidants to mitochondria: A new therapeutic direction. Biochim. Biophys. Acta, 2006; 1,762: 256-265

[29] Tie D., Da X., Natsuga K., Yamada N., Yamamoto O., Morita E.: Bullous pemphigoid IgG induces cell dysfunction and enhances the motility of epidermal keratinocytes via Rac1/proteasome activation. Front. Immunol., 2019; 10: 200

[30] Sarniak A., Lipińska J., Tytman K., Lipińska S.: Endogenous mechanisms of reactive oxygen species (ROS) generation. Postępy Hig. Med. Dośw., 2016; 70: 1,150-1,165 
[31] Bratic A., Larsson N.G.: The role of mitochondria in aging. J. Clin. Invest., 2013; 123: 951-957

[32] Wang C.H., Wu S.B., Wu Y.T., Wei Y.H.: Oxidative stress response elicited by mitochondrial dysfunction: Implication in the pathophysiology of aging. Exp. Biol. Med., 2013; 238: 450-460

[33] Maeshima E., Liang X.M., Goda M., Otani H., Mune M.: The efficacy of vitamin $E$ against oxidative damage and autoantibody production in systemic lupus erythematosus: A preliminary study. Clin. Rheumatol., 2007; 26: 401-404

[34] Shah A.A., Dey-Rao R., Seiffert-Sinha K., Sinha A.A.: Increased oxidative stress in pemphigus vulgaris is related to disease activity and HLA-association. Autoimmunity, 2016; 49: 248-257

[35] Casciola-Rosen L., Rosen A.: Ultraviolet light-induced keratinocyte apoptosis: A potential mechanism for the induction of skin lesions and autoantibody production in LE. Lupus, 1997; 6: 175-180

[36] Salimi S., Nakhaee A., Jafari M., Jahantigh D., Sandooghi M., Zakeri Z., Shahrakipour M., Naghavi A., Farajian-Mashhadi F.: Combination effect of GSTM1, GSTT1 and GSTP1 polymorphisms and risk of systemic lupus erythematosus. Iran. J. Public Health, 2015; 44: 814-821

[37] Glesse N., Rohr P., Monticielo O.A., Rech T.F., Brenol J.C., Xavier R.M., Kvitko K., Chies J.A.: Genetic polymorphisms of glutathione
S-transferases and cytochrome P450 enzymes as susceptibility factors to systemic lupus erythematosus in southern Brazilian patients. Mol. Biol. Rep., 2014; 41: 6,167-6,179

[38] Fraser P.A., Ding W.Z., Mohseni M., Treadwell E.L., Dooley M.A., St Clair E.W., Gilkeson G.S., Cooper G.S.: Glutathione S-transferase $\mathrm{M}$ null homozygosity and risk of systemic lupus erythematosus associated with sun exposure: A possible gene-environmental interaction for autoimmunity. J. Rheumatol., 2003; 30: 276-282

[39] Karlson E.W., Watts J., Signorovitch J., Bonetti M., Wright E., Cooper G.S., McAlindon T.E., Costenbader K.H., Massarotti E.M., Fitzgerald L.M., et al.: Effect of glutathione S-transferase polymorphisms and proximity to hazardous waste sites on time to systemic lupus erythematosus diagnosis: Results From the Roxbury Lupus Project. Arthritis Rheum., 2007; 56: 244-254

[40] Tew M.B., Reveille J.D., Arnett F.C., Friedman A.W., McNearney T., Fischbach M., Ahn C., Tan F.K.: Glutathione S-transferase genotypes in systemic sclerosis and their association with clinical manifestations in early disease. Genes Immun., 2001; 2: 236-238

[41] Palmer C.N., Young V., Ho M., Doney A., Belch J.J.: Association of common variation in glutathione S-transferase genes with premature development of cardiovascular disease in patients with systemic sclerosis. Arthritis Rheum., 2003; 48: 854-855 